\title{
Study of Degradation Processes of Feni Nanostructures
}

Kozlovskiy AL ${ }^{1,2}$, Korolkov IV $^{2}$, Borgekov DV ${ }^{1,2,3}$, Ibrayeva AD $^{1,2 *}$ and Zdorovets MV $^{1,2,3}$

${ }^{1}$ The Institute of Nuclear Physics of Republic of Kazakhstan, Almaty, Kazakhstan

${ }^{2}$ L.N. Gumilyov Eur Asian National University, Astana, Kazakhstan

${ }^{3}$ Ural Federal University named after the First President of Russia B.N. Yeltsin, Yekaterinburg, Russia

\begin{abstract}
The paper presents results of various media influence on the degradation processes of FeNi nanostructures obtained by electrochemical synthesis. The dependence of the change in the degradation degree on acidity and residence time in the medium has been found. By X-ray diffraction and energy dispersion analysis it has been determined that the change in the parameters of the crystal structure can be explained by the appearance of $\mathrm{FeO}$ oxide phases, as well as the formation of disorder areas, which appear as a result of oxidation processes and subsequent degradation.
\end{abstract}

Keywords: Nanotubes; Degradation; Electrochemical synthesis; Acidity; Crystal structure

\section{Introduction}

In the modern world more and more attention is paid to nanostructured materials, which in the future will take their place in almost all fields of science and technology: from magnetic recording devices to catalysts and drug carriers [1-4]. One of the founders of obtaining nanostructures, Martin and co-authors [5,6] showed a universal approach to obtain ordered arrays of nanostructures by a template synthesis method. Porous membranes based on alumina, polycarbonate or polyethylene terephthalate can be used as templates. An electrochemical deposition method is emphasized among the variety of methods [7-10] of obtaining nanostructures, its distinguishing features are simplicity, convenience, manufacture efficiency, as well as the ability to control the length and wall thickness, element and phase composition by changing the deposition conditions. In turn, one of the unique materials for practical use is an alloy of iron and nickel. NiFe nanostructures have unique physicochemical properties when the conditions of synthesis or chemical composition change, and it allows them to be one of the universal materials with a wide potential application [11-15]. Targeted delivery of drugs via the magnetic nanostructures takes a special place among the variety of practical applications of nanostructures. Groups of researchers discuss the type of nanostructures with optimal characteristics for use as containers for medicines [15-18]. Nanowires and nanotubes with their elongated shape and anisotropy of magnetic properties allow us to overcome the limitations of nanoparticles $[19,20]$. Compared with nanowires, nanotubes have some potential advantages, in particular, the absence of a magnetic core, which allows creating nanostructures with homogeneous switching fields that guarantee reproducibility of results [20]. A smaller specific density gives them an ability to float in liquids (including biological ones) and makes them suitable to use in biotechnology [21]. A large specific surface area provides a greater number of functional links and, correspondingly, the movement of a larger number of target components in precise drug delivery [22].

One of the important properties of nanotubes is their resistance to oxidation and degradation in environment with different acidity defined by the concentration of $\mathrm{H}^{+}$and $\mathrm{OH}^{-}$. In the absolutely clean water not containing even a dissolved gas concentrations of these ions are equal. Hydrogen index $(\mathrm{pH})$ is a value characterizing the concentration of hydrogen ions in solution. Deionized water, used from preparation of drug injection, has $\mathrm{pH}$ in the range 6.5-7, which is characteristic for the neutral and mildly acidic medium, $\mathrm{pH}$ of saline is $5.5, \mathrm{pH}$ of blood is 7.32-7.43.
This work demonstrates the degradation dynamics of $\mathrm{NiFe}$ nanotubes in various environments. According to these results the time frame of applicable of nanostructures and their degradation rate can be defined. Morphology and structure properties are studied using scanning electron microscopy and X-ray energy dispersive analysis.

\section{Material and Methods}

\section{Synthesis of $\mathrm{Fe}_{\mathrm{x}} \mathrm{Ni}_{100-\mathrm{x}}$ nanotubes}

$\mathrm{Fe}_{\mathrm{x}} \mathrm{Ni}_{100-\mathrm{x}}$ nanotubes (NT) were synthesized in pores of ion-track membranes based on polyethylenterephtalate (PET) of Hostaphan ${ }^{\circ}$ type (Mitsubishi Polyester Film GmbH, Germany) with a pore density of 4 $\times 10^{7} \mathrm{~cm}^{-2}$. Activation of $\mathrm{COOH}$ bonds formed as a result of chemical etching of tracks from heavy ions on surface of pore walls was carried out under UV sensitization of PET templates. This procedure made it possible to create localized charge states on pore walls that contributed to obtain the tubular shape of nanostructures at the electrochemical deposition stage.

Electrodeposition was carried out in the electrolyte of the composition $\mathrm{FeSO}_{4} \cdot 6 \mathrm{H}_{2} \mathrm{O}(20 \mathrm{~g} / \mathrm{L}), \mathrm{H}_{3} \mathrm{BO}_{3}(45 \mathrm{~g} / \mathrm{L})$, and $\mathrm{C}_{6} \mathrm{H}_{8} \mathrm{O}_{6}(1.5$ $\mathrm{g} / \mathrm{L}$ ) at cathode voltage of $1.75 \mathrm{~V}$ and temperature of $25^{\circ} \mathrm{C}, \mathrm{pH}$ of the solution was equal 3 . The cathode was a 10 -nm-thick gold film deposited using vacuum magnetron sputtering. This thickness of the gold film enabled pores to remain open, and the growth of the NTs began at sites of the contact of gold with the electrolyte (Figure $1 \mathrm{~b}$ and 1c). The electrodeposition process was monitored chronometrically using Agilent 34410A multimeter instrument.

\section{Methods}

The structural and morphological characteristics of NTs were studied by scanning electron microscopy (SEM) implemented in a Hitachi TM3030 scanning electron microscope equipped with a BrukerXFlash MIN SVE energy-dispersive analyzer (EDS) at an

*Corresponding author: Anel D lbrayeva, Ural Federal University named after the First President of Russia B.N. Yeltsin, Yekaterinburg, Russia, Tel: 73433745434; E-mail: anelusha1991@mail.ru

Received: June 20, 2017; Accepted: June 26, 2017; Published: June 30, 2017

Citation: Kozlovskiy AL, Korolkov IV, Borgekov DV, Ibrayeva AD, Zdorovets MV (2017) Study of Degradation Processes of Feni Nanostructures. J Nanomed Nanotechnol 8: 447. doi: 10.4172/2157-7439.1000447

Copyright: (c) 2017 Kozlovskiy AL, et al. This is an open-access article distributed under the terms of the Creative Commons Attribution License, which permits unrestricted use, distribution, and reproduction in any medium, provided the original author and source are credited. 


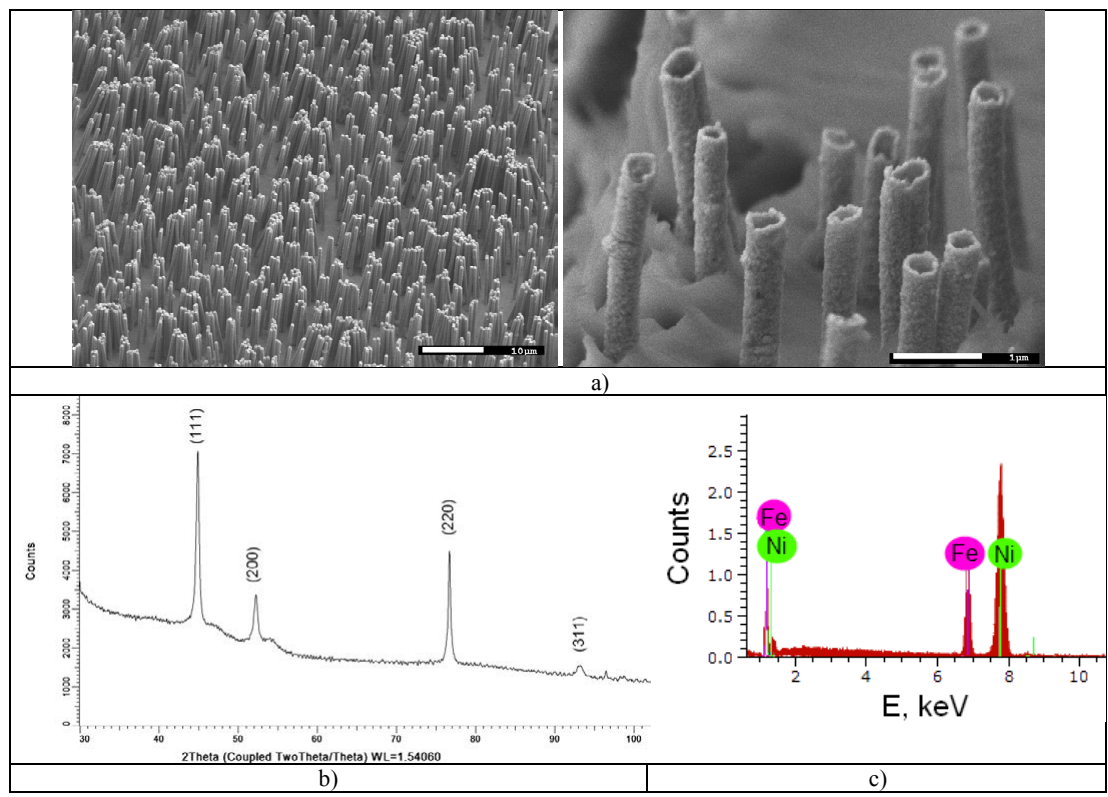

Figure 1: a) SEM images of pure nanotubes; b) XRD pattern; c) EDS spectrum of virgin sample.

accelerating voltage of $15 \mathrm{kV}$. Inner and outer diameters of the NTs formed in the PET template were measured by the manometric method of the gas permeability determination $[21,22]$ based on measuring a gas pressure in a closed chamber in the range of $8-20 \mathrm{kPa}$ with a step of 4 $\mathrm{kPa}$. X-ray diffraction structural analysis (XRD) was performed using D8 ADVANCE ECO diffractometer equipped with an X-ray tube with a copper anode and a graphite monochromator on a diffracted beam. XRD patterns were recorded in the angular range of $2 \theta=30^{\circ}-70^{\circ}$ with a step of $0.02^{\circ}$.

\section{Reactivity study}

Three aqueous solutions with different $\mathrm{pH}$ value ranging from $\mathrm{pH}=1$ (strongly acidic) to 7 (neutral) were selected to study the reactivity. The most common chemical reagent used to reduce the high $\mathrm{pH}$ of aqueous solutions is hydrochloric acid. The concentration of hydrogen ions in solutions increased gradually due to the use of slightly concentrated $(0.01 \mathrm{M})$ hydrochloric acid. The $\mathrm{pH}$ was monitored by a pH meter (Hanna Instruments HI2210-02).

To carry out the experiment the nanotubes were freed from the polymer matrix by dissolving it in an alkaline solution. A $9 \mathrm{M}$ solution of sodium hydroxide was used to etch the film. Pure nanotubes were placed in prepared aqueous solutions with different $\mathrm{pH}$ values for 1,5 , 10 and 20 days. At the end of each time interval changes in the structure and morphology of nanotubes were researched.

\section{Results and Discussion}

SEM images of obtained nanotubes are shown in Figure 1a. According to the SEM-microphotographs the tubes are isotropic and cylindrical, with a length of $12 \mu \mathrm{m}$ and an outer diameter of $400 \mathrm{~nm}$, corresponding to the pore size of the original template. The thickness of walls was $100 \mathrm{~nm}$. The XRD and EDS methods were used to determine the crystal structure and elemental composition. The diffraction pattern of the study sample (Figure 1b) demonstrates low-intensity peaks, characteristic for diffraction at nanoscale objects. The broadening of peaks indicates a polycrystalline structure of $\mathrm{Fe} / \mathrm{Ni}$ nanotubes. According to results of the X-ray diffraction analysis (XRD) the phase composition of virgin study samples corresponds to a substitutional alloy by iron atoms in nickel with a predominance of the fcc-phased $\mathrm{Ni}$ in the crystal structure of nanotubes with a cell parameter $a=3.5695 \AA$, different from the reference value ( $a=3.5154 \AA$, PDF № 031051), with the predominant texture [111].

The unit cell parameter can grow due to the difference in the atomic radii of nickel and iron. By EDS it has been determined that the atomic ratio of iron and nickel in nanotubes is equal to $21 \%$ and $79 \%$ respectively. At the same time, peaks typical for oxygen are not observed in the EDS spectrum, which indicates the absence of oxide compounds in the virgin samples.

The effect of the medium acidity on the crystal structure of $\mathrm{Fe} /$ $\mathrm{Ni}$ nanotubes has been studied by the method of EDS and XRD analysis. Figure 2 shows graphs of the elemental composition of nanotubes depending on the medium $\mathrm{pH}$ and the retention time in the corresponding solution.

According to the obtained data, the appearance of oxygen in the structure of nanotubes is observed on the $5^{\text {th }}$ day for media with $\mathrm{pH}=1$ and $\mathrm{pH}=5$, and it can lead to oxidation of nanotubes and partial amorphization.

According to the EDS analysis there has been studied the rate of oxidation reaction of nickel and iron that means the change in the concentration of substances per time unit. An integral method has been used to determine the order of the chemical oxidation reaction of nanotubes, depending on the medium acidity. The results are shown in Figure 3.

Anamorphosis character for various environments in coordinates $\ln \left(A_{0} /\left(A_{0}-x\right)\right)-t$, where $A_{0}$ is an initial substance concentration, $A_{0}-x$ is a current concentration in a given time, $t$ is the time described by a straight line, confirming that the oxidation process of nanotubes is a first order reaction.

The X-ray diffraction method was used to determine the oxidation products of $\mathrm{FeNi}$ nanotubes. Figures 4-6 show X-ray diffraction patterns of study samples in media with different $\mathrm{pH}$. 


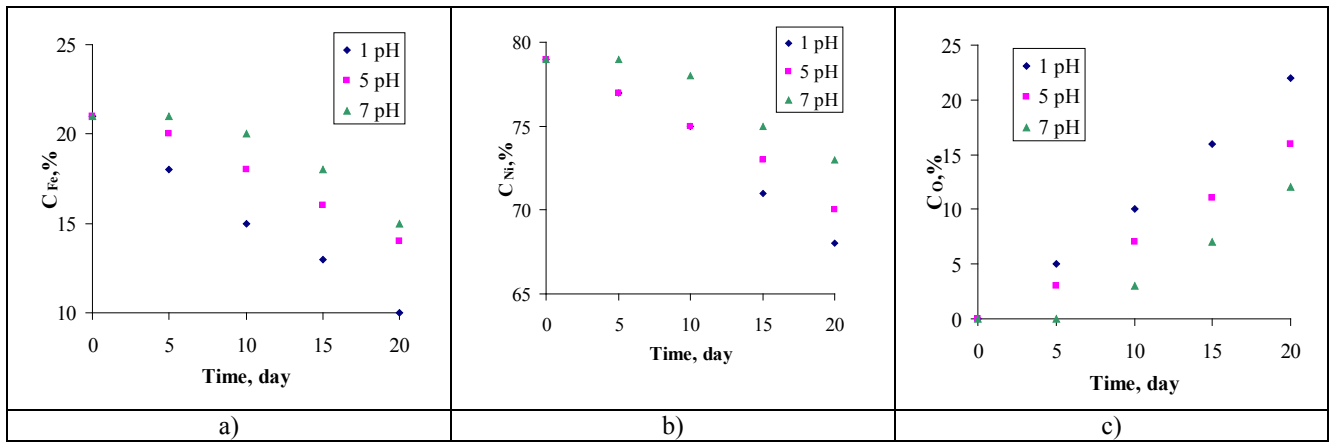

Figure 2: Dependence of the atomic content of iron (A), nickel (B) and oxygen (C) in nanotubes on the residence time in solution with pH - 1, 5, 7 .

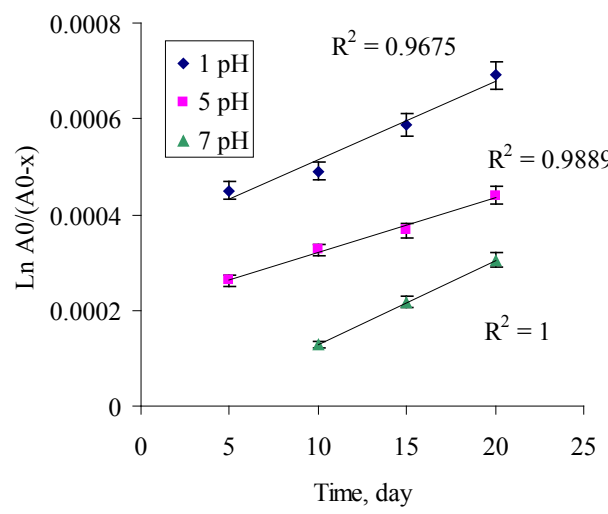

Figure 3: Anamorphosis of the kinetic curve for the oxidation and degradation reaction.

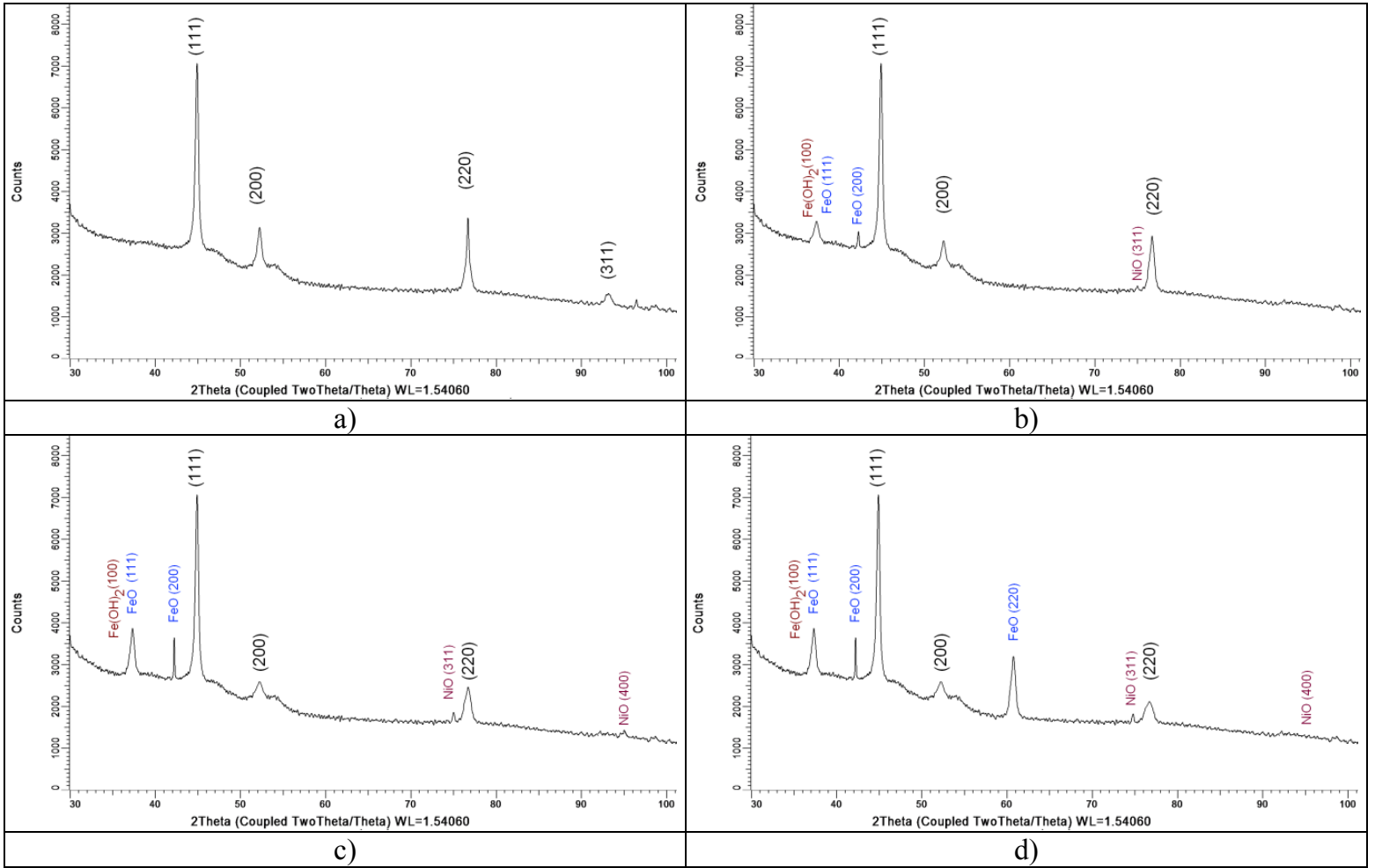

Figure 4: $\mathrm{XRD}$ patterns of Fe/Ni nanotubes in medium with $\mathrm{pH}=1$ for a) 5 days, b) 10 days, c) 15 days, d) 20 days 
Citation: Kozlovskiy AL, Korolkov IV, Borgekov DV, Ibrayeva AD, Zdorovets MV (2017) Study of Degradation Processes of Feni Nanostructures. J Nanomed Nanotechnol 8: 447. doi: 10.4172/2157-7439.1000447

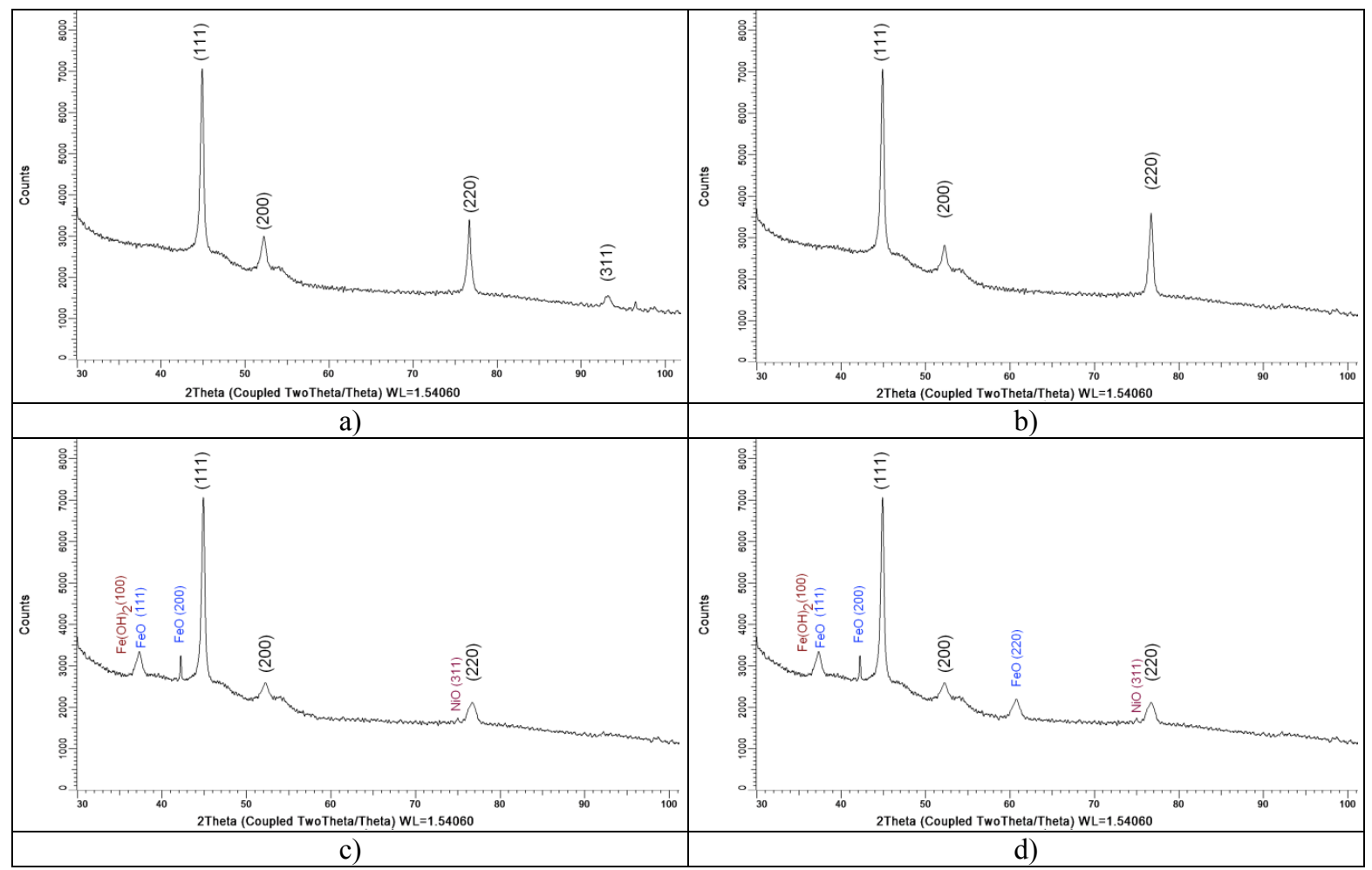

Figure 5: XRD patterns of Fe/Ni nanotubes in medium with $\mathrm{pH}=5$ for a) 5 days, b) 10 days, c) 15 days, d) 20 days.

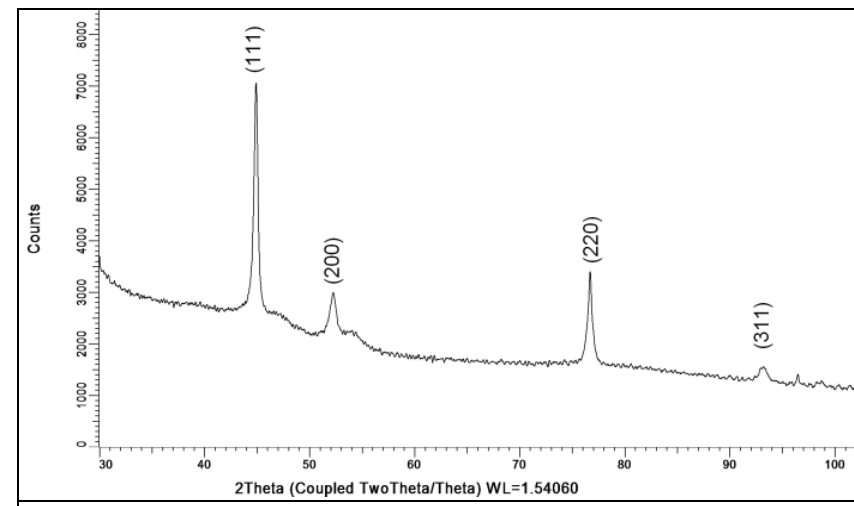

a)

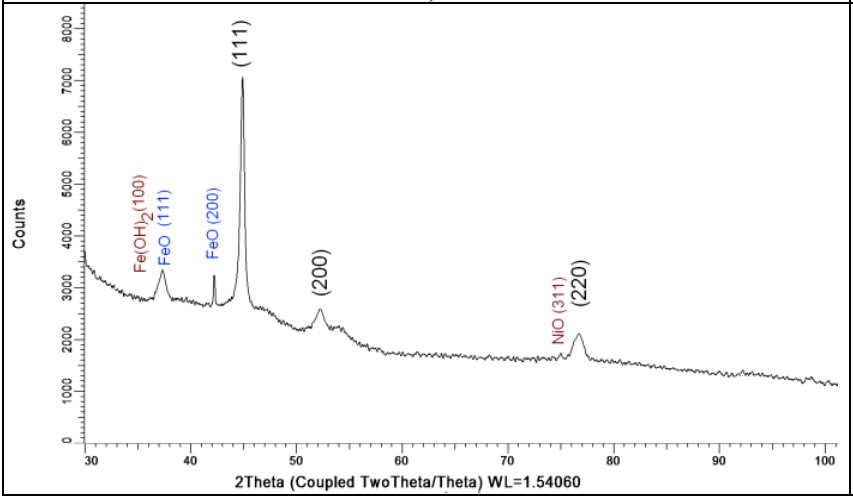

c)

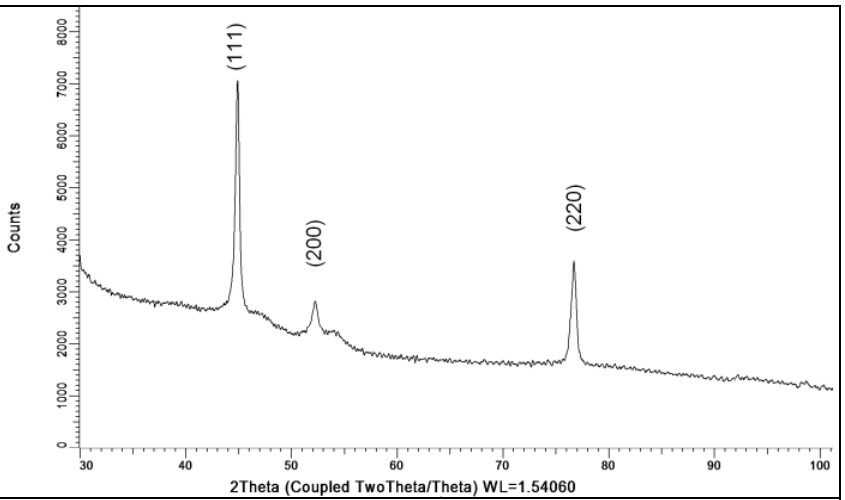

b)

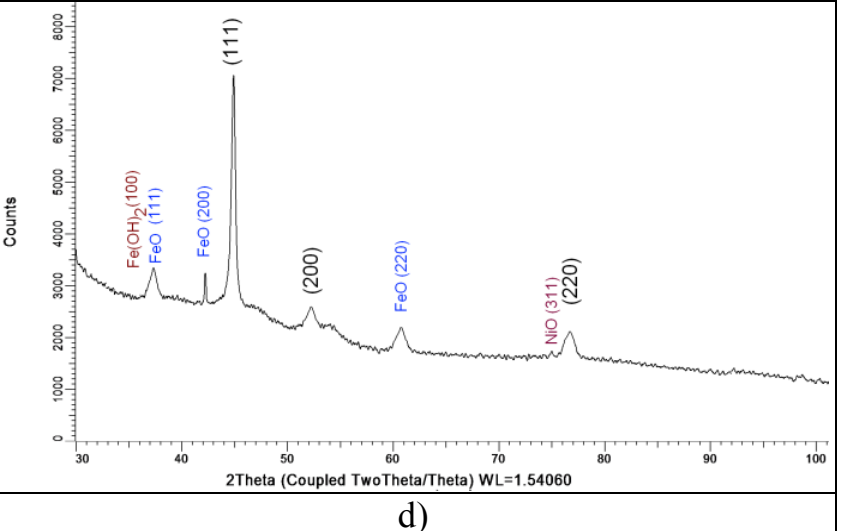

d)

Figure 6: XRD patterns of Fe/Ni nanotubes in medium with $\mathrm{pH}=7$ for a) 5 days, b) 10 days, c) 15 days, d) 20 days 
Based on analyzing the nature of changes in intensity and shape of peaks of the diffraction patterns it is possible to make an assumption about the structure amorphization and partial degradation of nanotubes in acidic media after 10 days in medium with $\mathrm{pH}=1$ and 5. Additionally, on diffraction patterns there are peaks typical for hydroxide $\mathrm{Fe}(\mathrm{OH})_{2}$ and iron oxides $\mathrm{FeO}$ on the $10^{\text {th }}$ day for aggressive media, and on $15^{\text {th }}$ day for media with $\mathrm{pH}=5$. Also, there are low-intensity peaks typical for nickel oxide $\mathrm{NiO}$ with Miller indices (311) and (400) on the diffraction patterns. At the same time, according to the obtained diffractograms as the residence time in solutions increases, the intensity of the peaks characteristic for the nickel phase decreases, while the intensity of the peaks of the oxide phases $\mathrm{Fe}(\mathrm{OH})_{2}$ and $\mathrm{FeO}$ rises. Based on the analysis of the shape of peaks, the contributions of various phases to the crystal structure of nanotubes were obtained during the oxidation process. The results of the assessment of contributions are presented in Table 1.

As can be seen from the presented data, the hydroxide phase of the $\mathrm{Fe}(\mathrm{OH})_{2}$ and oxide phase of $\mathrm{FeO}$ begins forming on the 10th day for nanotubes, when the oxygen content in the structure of nanotubes exceeds $10 \%$. At the same time, for nanotubes in neutral media, the presence of oxide phases is not detected, but according to the data of EDS analysis, the appearance of oxygen is observed, probably the oxide phase is formed only on the surface of nanotubes.

Analysis of X-ray diffraction patterns made it possible to estimate the crystallinity degree of the obtained nanotubes, and also to follow up the dynamics of the amorphization process of the crystal structure in media with different $\mathrm{pH}$. Figure 7 demonstrates the diagram of changes in the crystallinity degree during the experiment.

As can be seen from the presented data, the crystallinity degree has reduced from $91 \%$ for the virgin sample to $65 \%$ on the $15^{\text {th }}$ day and $54 \%$ on the $20^{\text {th }}$ day for the medium with $\mathrm{pH}=1$, and to $73 \%$ on $15^{\text {th }}$ day and $66 \%$ on the $20^{\text {th }}$ day for the medium with $\mathrm{pH}=5$. It has been found that a decline of the crystallinity degree below $70 \%$ leads to a high degree of the structure amorphization and partial structure destruction due to the formation of oxide compounds on the surface of nanotubes and subsequent corrosion processes that can cause structural destruction.

According to the obtained data, the appearance of $\mathrm{FeO}$ oxide compounds in the structure of nanotubes is typical when the crystallinity degree decreases below $70 \%$. Oxide compounds of nickel have not been found in the structure. In turn, an insignificant fall of the crystallinity degree is observed for samples in a medium with $\mathrm{pH}=7$, as well as peaks typical for oxide compounds of nickel and iron are absent in the diffraction patterns.

Figure 6a shows the dependence of the lattice parameter $a$ on the residence time in a medium with different $\mathrm{pH}$, obtained using the Nelson-Taylor extrapolation function:

$$
a=f\left(\frac{1}{2}\left(\frac{\cos ^{2} \theta}{\sin \theta}+\frac{\cos \theta}{\theta}\right)\right.
$$

The value and error of determining the parameter $a$ were obtained by linear extrapolation of this function to the zero value of the argument $\left(\theta=90^{\circ}\right)$. The increase in the parameter $a$ for a medium with $\mathrm{pH} 1$ can be explained by the appearance of hydroxide and oxide phases in the structure. In the case of a medium with a $\mathrm{pH}$ of 7 , an insignificant growth of the lattice parameter is observed, which indicates a low rate of nanotubes' oxidation in neutral media.

At the same time, the growth of the average crystallite size is observed (Figure 8), which is directly related to the appearance of hydroxide and oxide phases in the form of corrosion outgrowths, as well as the formation of disorder areas in the crystal structure.

The dynamics of the crystallite shapes and the orientation of the $\mathrm{Fe}_{\mathrm{x}} \mathrm{Ni}_{100-\mathrm{x}}$ nanotubes as a result of oxidation has been studied by estimating the texture coefficients of nanotubes. Crystallographic texture is named the predominant orientation of grains in a polycrystal. The texture coefficients have been calculated by the Harris formula:

$$
T C_{h k l}=\frac{I_{h k l}}{I_{0 h k l}} /\left(\frac{1}{n} * \sum \frac{I_{h k l}}{I_{0 h k l}}\right)
$$

\begin{tabular}{|c|c|c|c|c|c|c|c|c|c|c|c|c|}
\hline \multirow[t]{2}{*}{ Time } & \multicolumn{4}{|c|}{$1 \mathrm{pH}$} & \multicolumn{4}{|c|}{$5 \mathrm{pH}$} & \multicolumn{4}{|c|}{$7 \mathrm{pH}$} \\
\hline & $\mathrm{Ni}$ & $\mathrm{FeO}$ & $\mathrm{Fe}(\mathrm{OH})_{2}$ & $\mathrm{NiO}$ & $\mathrm{Ni}$ & $\mathrm{FeO}$ & $\mathrm{Fe}(\mathrm{OH})_{2}$ & $\mathrm{NiO}$ & $\mathrm{Ni}$ & $\mathrm{FeO}$ & $\mathrm{Fe}(\mathrm{OH})_{2}$ & $\mathrm{NiO}$ \\
\hline 0 & 100 & - & - & - & 100 & - & - & - & 100 & - & - & - \\
\hline 5 days & 100 & - & - & - & 100 & - & - & - & 100 & - & - & - \\
\hline 10 days & 91 & 6 & 2 & 1 & 100 & & - & - & 100 & - & - & - \\
\hline 15 days & 86 & 9 & 3 & 2 & 94 & 3 & 2 & 1 & 100 & - & - & - \\
\hline 20 days & 77 & 15 & 5 & 3 & 88 & 7 & 3 & 2 & 100 & - & - & - \\
\hline
\end{tabular}

Table 1: Data on the phase state of nanotubes, $\%$.

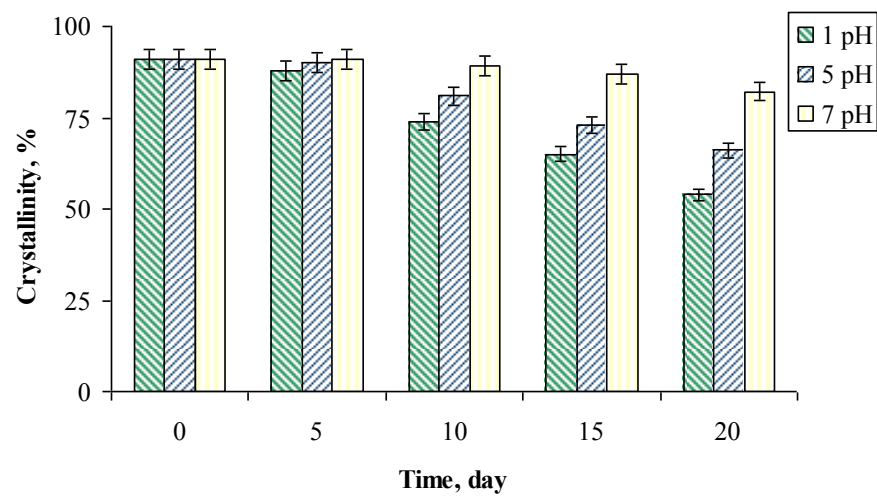

Figure 7: Diagram of the changes in the crystallinity degree. 


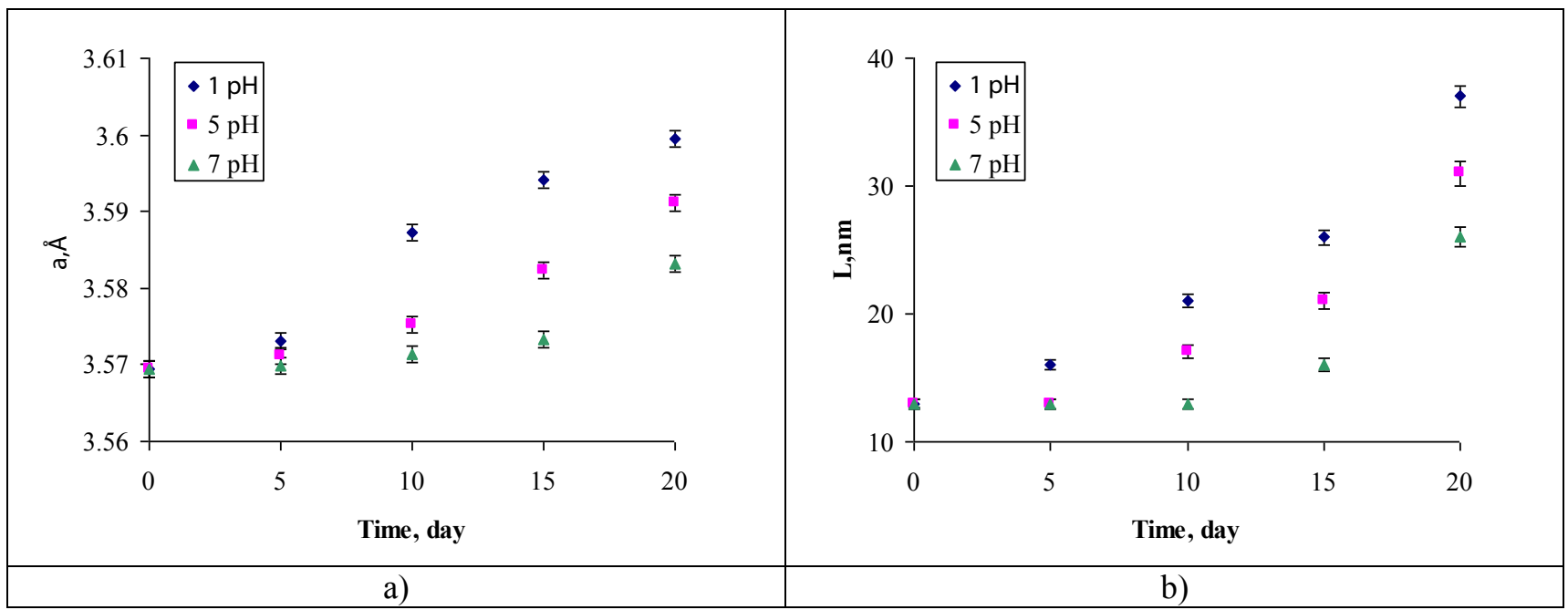

Figure 8: Characteristics of the crystal structure of the obtained samples of nanotube arrays: a) unit cell parameter; b) the average size of crystallites.

\begin{tabular}{|c|c|c|c|c|c|c|c|c|c|c|c|c|c|c|c|}
\hline \multirow[t]{2}{*}{$h k l$} & \multicolumn{5}{|c|}{ pH 1} & \multicolumn{5}{|c|}{ pH 5} & \multicolumn{5}{|c|}{ pH 7} \\
\hline & Pristine & 5 days & Pristine & 5 days & 10 days & 15 days & 20 days & 10 days & 15 days & 20 days & Pristine & 5 days & 10 days & 15 days & 20 days \\
\hline $\mathrm{Ni}(111)$ & 1.6441 & 1.5615 & 1.6441 & 1.6415 & 1.6351 & 1.5635 & 1.5151 & 1.3211 & 1.1142 & 1.0515 & 1.6441 & 1.6142 & 1.5511 & 1.4521 & 1.2522 \\
\hline $\mathrm{Ni}(200)$ & 0.9412 & 0.8415 & 0.9412 & 0.9146 & 0.9121 & 0.9024 & 0.8781 & 0.7514 & 0.5252 & 0.3111 & 0.9412 & 0.9341 & 0.7472 & 0.6521 & 0.6521 \\
\hline $\mathrm{Ni}(220)$ & 0.7621 & 0.5315 & 0.7621 & 0.7351 & 0.7145 & 0.6954 & 0.6721 & 0.5214 & 0.3451 & 0.2141 & 0.7621 & 0.7214 & 0.6721 & 0.5352 & 0.4141 \\
\hline $\mathrm{Ni}(311)$ & 0.4521 & - & 0.4521 & 0.4511 & - & - & - & - & - & - & 0.4521 & 0.3515 & - & - & - \\
\hline $\mathrm{FeO}(111)$ & - & - & & & & & & 0.4214 & 0.5782 & 0.8732 & - & - & - & 0.5321 & 0.6532 \\
\hline $\mathrm{FeO}(200)$ & - & - & & & & & & 0.3412 & 0.5451 & 0.7472 & - & - & - & 0.4314 & 0.5632 \\
\hline $\mathrm{FeO}(220)$ & - & - & & & & & & - & - & 0.5578 & - & - & - & - & 0.4251 \\
\hline $\begin{array}{c}\mathrm{Fe}(\mathrm{OH})_{2} \\
(100)\end{array}$ & - & - & & & & & & 0.1314 & 0.2781 & 0.4662 & - & - & - & 0.2413 & 0.3214 \\
\hline $\mathrm{NiO}(311)$ & - & - & & & & & & 0.1135 & 0.1642 & 0.2461 & - & - & - & 0.1314 & 0.1879 \\
\hline
\end{tabular}

Table 2: Data of texture coefficients.

Where $I_{h k l}$ is the experimentally obtained intensity of the reflex, $I_{0 h k l}$ is the corresponding intensity according to the JCPDS base, and $n$ is the number of reflexes. The results of the calculations are given in Table 2.

Texture coefficients more than one indicate the predominant orientation of the array of nanotubes along the corresponding directions, which implies an increase in the number of grains along these directions. The number of reflections (n) corresponds to the maximum value of the texture coefficients. According to the analysis of the obtained data, the texturing degree decrease in the acid medium with $\mathrm{pH}=1$ while the content of oxide compounds increase, which leads to amorphization of nanotubes. In the case of neutral media, the change in the texture coefficients is negligible.

From the above data, it can be summarized that a typical oxidation of iron and nickel occurs. Iron is oxidized to $\mathrm{Fe}^{2+}$ in an acidic medium. Mechanisms of iron oxidation have been studied well by the authors [23-25]. The reaction equations are shown in Scheme 1.

At the same time, when the FeNi nanotubes are kept in more aggressive media, also the nickel oxidizes, that proceeds by loss of electrons during interaction with the medium and transition to nickel oxide (II):

$$
\mathrm{Ni}^{0}-2 e=\mathrm{Ni}^{2+} .
$$

The obtained nickel oxide (II) refers to berthollides with oxygen stoichiometry. When much oxygen is in the structure, it passes into

$$
\begin{aligned}
& \mathrm{Fe}(\mathrm{s})+1 / 2 \mathrm{O}_{2}(\mathrm{~g}) \leftrightarrow \mathrm{FeO}(\mathrm{s}) \\
& \mathrm{Fe}(\mathrm{s})+2 \mathrm{H}_{2} \mathrm{O}+\mathrm{O}_{2} \rightarrow 2 \mathrm{Fe}(\mathrm{OH})_{2}(\mathrm{~s}) \\
& \mathrm{Fe}(\mathrm{s})+2 \mathrm{H}^{+} \rightarrow \mathrm{Fe}^{2+}(\mathrm{I})+\mathrm{H}_{2}(\mathrm{~g}) \\
& \mathrm{Fe}(\mathrm{OH})_{2}(\mathrm{~s})+2 \mathrm{HCl} \rightarrow \mathrm{FeCl}_{2}(\mathrm{I})+2 \mathrm{H}_{2} \mathrm{O} \\
& \mathrm{FeO}(\mathrm{s})+2 \mathrm{HCl} \rightarrow \mathrm{FeCl}_{2}(\mathrm{I})+\mathrm{H}_{2} \mathrm{O}
\end{aligned}
$$

Scheme 1: The reaction equations of the iron oxidation.

nickel oxide (III) of $\mathrm{Ni}_{2} \mathrm{O}_{3} \cdot \mathrm{H}_{2} \mathrm{O}$ or $\mathrm{NiOOH}$. In this case, nickel ions are completely oxidized:

$$
\mathrm{Ni}^{2+}-1 e=\mathrm{Ni}^{3+} \text {. }
$$

However, since the oxidation state +3 is not typical for nickel, compounds with this valency are unstable, so the hydrated forms of nickel oxide (II) fragment with oxygen release.

According to the results of SEM, the corrosion outgrowths are forming on nanotubes, and then gradually dissolving with increasing the residence time according to the chemical transformations presented in Scheme 1, and probably the interaction of ferric hydroxide with hydrochloric acid occurs faster than iron oxide, so predominantly the iron oxide (II) phase is detected on the tubes. 
Citation: Kozlovskiy AL, Korolkov IV, Borgekov DV, Ibrayeva AD, Zdorovets MV (2017) Study of Degradation Processes of Feni Nanostructures. J Nanomed Nanotechnol 8: 447. doi: 10.4172/2157-7439.1000447

Page 7 of 8

Figure 9 demonstrates SEM images showing the degradation dynamics of $\mathrm{Fe}_{\mathrm{x}} \mathrm{Ni}_{100-\mathrm{x}}$ nanotubes in various media. According to the analysis of the obtained images the greatest degradation of nanotubes is observed for acid media with $\mathrm{pH}=1$, which confirms the results of the change in the crystal structure and the reactivity calculation. The photographs clearly illustrate that for the medium with $\mathrm{pH}=1$ on the

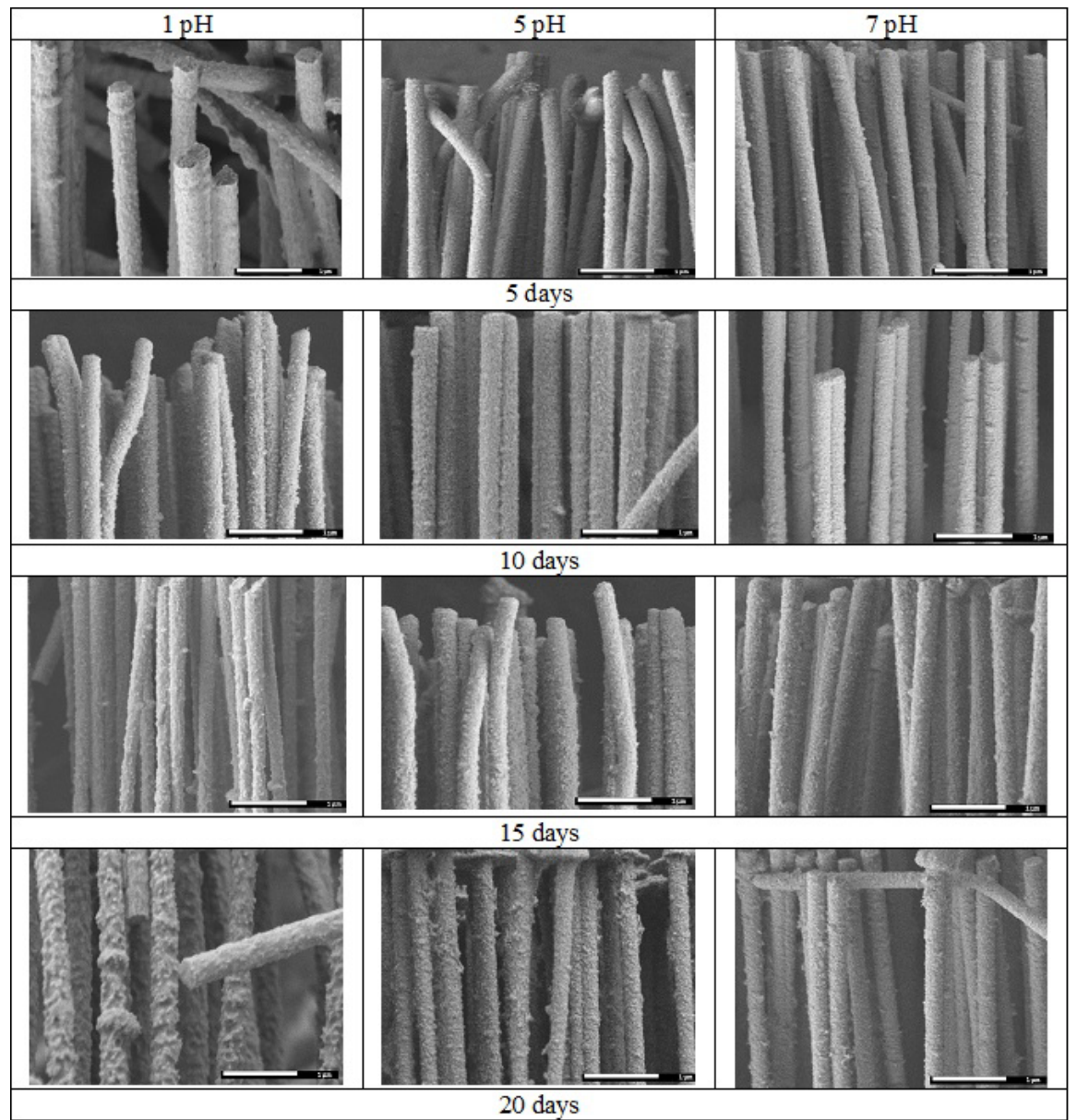

Figure 9: SEM images of changes in the surface morphology of $\mathrm{Fe}_{x} \mathrm{Ni}_{100-x}$ nanotubes as a function of the medium acidity.
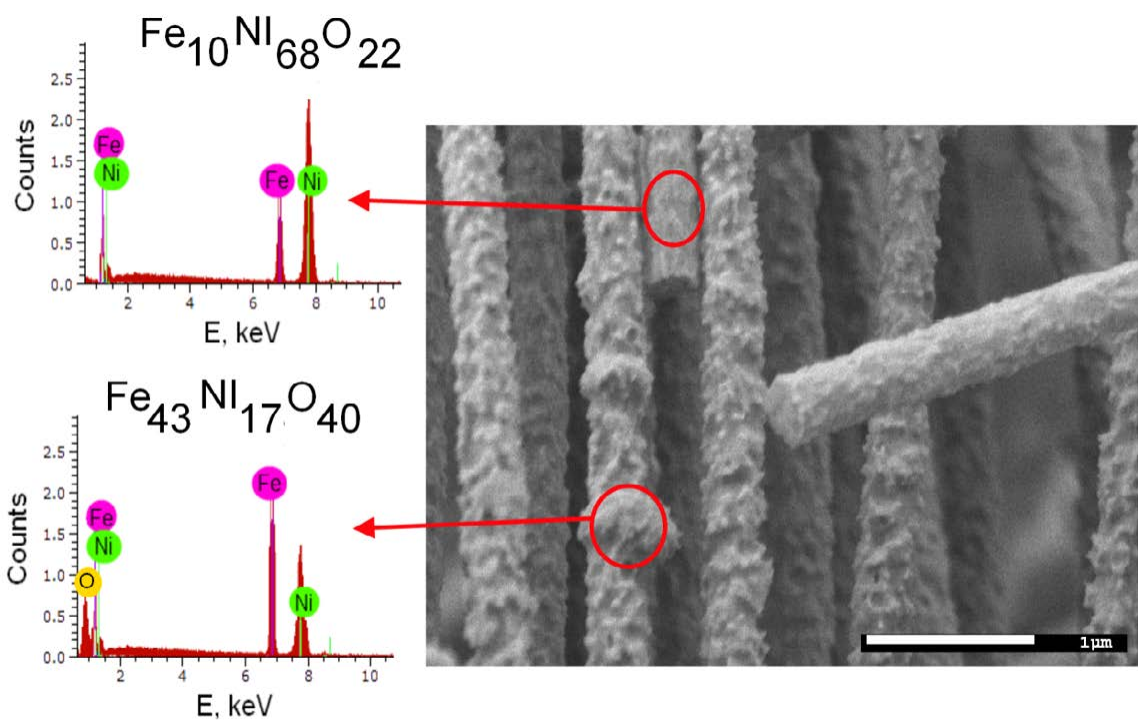

Figure 10: The detailed EDS analysis of outgrowths on nanotubes. 
Citation: Kozlovskiy AL, Korolkov IV, Borgekov DV, Ibrayeva AD, Zdorovets MV (2017) Study of Degradation Processes of Feni Nanostructures. J Nanomed Nanotechnol 8: 447. doi: 10.4172/2157-7439.1000447

Page 8 of 8

$10^{\text {th }}$ day outgrowths form on the surface of nanotubes, consisting of oxide compounds, according to the data of EDS and XRD. A detailed analysis of the outgrowths is shown in Figure 10.

As can be seen from the presented EDS data, a high concentration of oxygen and iron is observed on nanotubes, which indicates the oxide structure of the outgrowths. On the 15th and 20th day, there is an increase in the number of outgrowths that cause the amorphization of nanotubes' surface, which confirms the results of these changes in the crystallinity degree. According to the EDS analysis for media with $\mathrm{pH}=5$ and $\mathrm{pH}=7$ the oxygen appearance in the structure is observed on the $5^{\text {th }}$ day for $\mathrm{pH}=5$ and on the $10^{\text {th }}$ day for $\mathrm{pH}=7$, but based on XRD data, oxide compounds in the crystal structure appear on the $15^{\text {th }}$ day for the medium with $\mathrm{pH}=5$. The presence of small oxygen impurities on the $5^{\text {th }}$ day is due to the surface layer oxidation of nanotubes.

\section{References}

1. Wu D (2017) Fe3O4/FeNi embedded nanostructure and its kinetic law for selective catalytic reduction of p-nitrophenyl compounds. Inorganic Chemistry.

2. Cristea C, Tertis M, Galatus R (2017) Magnetic Nanoparticles for Antibiotics Detection. Nanomaterials 7: 119.

3. Wang P, Du M, Zhang M, Zhu H, Bao S, et al. (2014) Facile fabrication of AuNPs/PANI/HNTs nanostructures for high-performance electrochemical sensors towards hydrogen peroxide. Chem Eng J 248: 307-314.

4. Li C, Li X, Duan X, Li G, Wang J (2014) Halloysite nanotube supported Ag nanoparticles heteroarchitectures as catalysts for polymerization of alkylsilanes to superhydrophobic silanol/siloxane composite microspheres. J Colloid Interface Sci 436: 70-76.

5. Martin CR (1994) Nanomaterials: A Membrane-Based Synthetic Approach. Science 266: 1961-1966.

6. Klein JD, Herric RD, Palmer D, Sailor MJ, Brumlik CJ (1993) Electrochemical Nanofabrication: Principles and Applications. (2nd Edtn) Chem Mater 5: 902.

7. Sehayek T, Lahav M, Popovitz-Biro R, Vaskevich A, Rubinstein I (2005) Chem Mater 17: 3743.

8. Li Y, Wang J, Deng Z, Wu Y, Sun X, et al. (2001) Colloids Seeded Deposition: Growth of Titania Nanotubes in Solution. J Am Chem Soc 123: 9904.

9. Haehnel V, Fähler S, Schaaf P, Miglierini M, Mickel C, et al. (2010) Structure, Microstructure, and Magnetism of Electrodeposited Fe70Pd30 Nanowires. J Phys Chem 58: 2330-2337.

10. Chen Y, Xu C, Zhou Y, Maaz K, Yao H, et al. (2016) Temperature and
Angle-Dependent Magnetic Properties of Ni Nanotube Arrays Fabricated by Electrodeposition in Polycarbonate Templates. Nanomaterials 6: 231.

11. Zhong S, Zhou C, Zhang X, Zhou H, Li H, et al. (2014) A novel molecularly imprinted material based on magnetic halloysite nanotubes for rapid enrichment of 2,4-dichlorophenoxyacetic acid in water, J. Hazard. Mater.276: 58-65.

12. Yen SK, Padmanabhan P, Selvan ST (2013) Multifunctional iron oxide nanoparticles for diagnostics, therapy and macromolecule delivery. Theranostics 3: 986-1003.

13. Kim C, Torati S, Reddy V, Yoon S (2015) Protein immobilization onto electrochemically synthesized CoFe nanowires. 645.

14. Dragos O (2016) Anomalous Codeposition of fcc NiFe Nanowires with 5-55\% Fe and Their Morphology, Crystal Structure and Magnetic Properties. Journal of the Electrochemical Society 163: D83-D94.

15. Frolov K, Zagorskii D, Lyubutin I (2017) Magnetic and structural properties of $\mathrm{Fe}-\mathrm{Co}$ nanowires fabricated by matrix synthesis in the pores of track membranes.105: 319.

16. Tian X, Wang W, Tian N, Zhou C, Yang C, et al. (2016) $\mathrm{Cr}(\mathrm{VI})$ reduction and immobilization by novel carbonaceous modified magnetic Fe3O4/halloysite nanohybrid. J Hazard Mater 309: 151-156.

17. Pankhurst Q, Connolly J, Joness, Dobson J (2003) Applications of magnetic nanoparticles in biomedicine. Journal of Physics D: Applied Physics, 36: 167-181.

18. Yoshida Y, Fukui S, Fujimoto S, Mishima F, Takeda S, et al. (2017) Ex vivo investigation of magnetically targeted drug delivery system. Journal of Magnetism and Magnetic Materials 310: 2880-2882.

19. Kozlovskiy A, Zhanbotin A, Zdorovets M, Rusakov VS, Kadyrzhanov KK, et al (2016) Mossbauer research of $\mathrm{Fe} / \mathrm{Co}$ nanotubes based on track membranes. Nuclear Instruments and Methods in Physics Research 381: 103-109.

20. Hirota Y, Akiyama Y, Izumi Y, Nishijima S (2009) Fundamental study for development magnetic drug delivery system.469: 1853-1856.

21. Goodwin S, Peterson C, Hoh C, Bittner C (1999) Targeting and retention of magnetic targeted carriers (MTCs) enhancing intra-arterial chemotherapy. 194: 132-139.

22. Yen SK, Padmanabhan P, Selvan ST (2013) Multifunctional iron oxide nanoparticles for diagnostics therapy and macromolecule delivery. 3: 9861003.

23. Giri S, Ganguli S, Bhattacharya M (2001) Surface oxidation of iron nanoparticles. 182: $345-349$

24. Ruusunen J (2014) Controlled oxidation of iron nanoparticles in chemical vapour synthesis. J Nanoparticle Res 16: 2270.

25. Schwaminger SP, Bauer D, Fraga-García P, Wagnerb FE, Berensmeier S (2017) Oxidation of magnetite nanoparticles: impact on surface and crystal properties. Cryst Eng Comm 19: 246-255. 